\title{
Dynamics of Lettuce Drop Incidence and Sclerotinia minor Inoculum Under Varied Crop Rotations
}

\author{
J. J. Hao and K. V. Subbarao, Department of Plant Pathology, University of California, Davis, c/o U.S. Agricultural \\ Research Station, 1636 E. Alisal St, Salinas, CA 93905
}

\begin{abstract}
Hao, J. J., and Subbarao, K. V. 2006. Dynamics of lettuce drop incidence and Sclerotinia minor inoculum under varied crop rotations. Plant Dis. 90:269-278.

Field experiments were conducted to determine the population dynamics of Sclerotinia minor and incidence of lettuce drop at two sites during 1995 to 1998. Rotation treatments at the Spence site, which had a low density of inoculum $\left(<7\right.$ sclerotia per $100 \mathrm{~cm}^{3}$ of soil $)$ that was distributed randomly, included: continuous lettuce (LLL), lettuce rotated with broccoli (LBL), and lettuce followed by a fallow period (LFL). Treatments at the Hartnell site, which had a high density of inoculum ( $>7$ sclerotia per $100 \mathrm{~cm}^{3}$ of soil) that was distributed uniformly, included: continuous lettuce (LLLL), alternate crops of broccoli and lettuce (BLBL), continuous broccoli or lettuce (BBLL), and fallow-lettuce-fallow-lettuce (FLFL). Under continuous lettuce cropping (LLLL) at the Hartnell site, a progressively aggregated spatial pattern of inoculum distribution developed, despite the initial uniform distribution of high inoculum density. In the fallow treatment (FLFL), the spatial pattern tended to be aggregated following a lettuce crop and less aggregated or random when left fallow. In contrast to these two treatments, treatments involving rotations with broccoli (BLBL and BBLL) exhibited consistently random spatial patterns of inoculum regardless of the crop in the field. The marginal increases in the number of sclerotia contributed by the few diseased lettuce plants were offset by the significant reductions in the number of sclerotia by the broccoli residue. Spatial patterns of disease incidence reflected the pattern of inoculum distribution in the soil at the Hartnell site. Higher inoculum density coupled with an aggregated distribution was associated with an aggregation in disease incidence. At Spence, this correlation was poor in most seasons because of progressive decline in the lettuce drop incidence and lack of treatment differences. In greenhouse experiments, the competence volume for $S$. minor sclerotia was quantified, which was calculated to be $25 \mathrm{~cm}^{3}$ for $100 \%$ infection and $200 \mathrm{~cm}^{3}$ for $50 \%$ infection. Thus, in $100 \mathrm{~cm}^{3}$ of soil, a minimum of four to five sclerotia are needed for $100 \%$ of infection, explaining the high correlation between inoculum density and disease incidence.
\end{abstract}

Lettuce (Lactuca sativa L.) is an important cool-season vegetable crop grown in coastal California. Production of lettuce in this area occurs nearly all year except for a brief "lettuce-free" period mandated for the management of Lettuce mosaic virus. In the San Joaquin Valley and the desert areas, lettuce production occurs only during the winter. In the coastal areas, often two crops of lettuce are produced in the same field, which has the potential to exacerbate many soilborne diseases.

Lettuce drop, caused by Sclerotinia minor Jagger, is an important soilborne disease that results in yield losses in all lettuce growing areas, especially in California $(7,12,26)$. The pathogen produces large numbers of sclerotia on diseased lettuce plants, augmenting soil inoculum levels $(11,14)$. Sclerotia are the major means of pathogen survival and

Corresponding author: K. V. Subbarao

E-mail: kvsubbarao@ucdavis.edu

Accepted for publication 7 September 2005.

DOI: 10.1094/PD-90-0269

(C) 2006 The American Phytopathological Society spread, and the primary source of inoculum (18). Mycelia from germinated sclerotia infect plants directly $(1,22)$.

Repeated lettuce cropping leads to increased accumulation of $S$. minor sclerotia in soil and increased disease incidence on ensuing lettuce crops (25). Since sclerotia are critical for survival and infection by $S$. minor, control methods have attempted to reduce the number and viability of sclerotia $(3,4,21,27)$. In recent years, rotation with pathogen suppressive plant species has drawn increasing attention as an important disease management tool in sustainable agriculture $(6,12,29)$. A number of Brassica species are candidates for crop rotation because of the suppressive properties of their chemical constituents and their consequent ability to reduce the number of plant pathogen propagules and disease incidence or severity (17). Rotations of crops susceptible to Verticillium dahliae Kleb. with broccoli (Brassica oleracea L. var. botrytis L.) have significantly reduced the number of $V$. dahliae microsclerotia in soil and the incidence of wilt on susceptible crops $(24,29)$. Rotations of lettuce with broccoli also reduced numbers of $S$. minor sclerotia and the incidence of lettuce drop (12). How these rotations affect the spatial and temporal dynamics of sclerotial populations and the epidemiology of lettuce drop is not well described.

Soil management practices such as deep-plowing have been documented to change the spatial distribution of sclerotia in soil (27). Deep-plowing alters the established high-inoculum-density, aggregated distribution of $S$. minor sclerotia to lowerdensity, random distribution because of the greater than normal tillage operations needed to prepare soil for planting after deep-plowing (27). Because of this altered density and distribution of $S$. minor sclerotia, greater drop incidence in succeeding lettuce crops is observed. The system is also energy-intensive and is therefore unlikely to be an efficacious practice in the high-inoculum-density fields in the Salinas Valley. While providing the first comprehensive data on the effects of deepplowing, the study was also one of the few to relate the effects of field operations to changes in density and distribution of soilborne propagules (27).

Competence volume was a concept developed for soilborne pathogens to describe the volume of soil encompassing the maximum depth and distance from where a pathogen can infect its host $(8,9,20)$. This concept may apply particularly well to $S$. minor on lettuce (14) because of the static nature of the $S$. minor sclerotia in soil, the taproot system in lettuce, and the limited distance from which the mycelia from germinated sclerotia can infect lettuce plants. Determining the competence volume for $S$. minor could lead to a better understanding of the relationship between inoculum density and disease incidence (ID-DI) $(5,8,9,20)$, better soil sampling strategies, and improved methods to determine the efficacy of control strategies.

The objectives of this study were (i) to determine the spatial and temporal dynamics of $S$. minor sclerotia in soil and incidence of lettuce drop under various rotations, and (ii) to experimentally evaluate the competence volume of $S$. minor sclerotia.

\section{MATERIALS AND METHODS}

Field plot preparation and cropping. The experiments were conducted at the Spence Road site of the United States Department of Agriculture Research Station and the Hartnell College East Campus, both in Salinas, CA, during 1995 to 1998 (12). The field and crop maintenance, such 
as bed preparation, planting, and harvesting, was similar to standard commercial production. Lettuce was planted twice a year, coinciding with either the spring (April through June) or fall (July through October) seasons, and designated as spring or fall crops. The lettuce cultivar Salinas (Pybas Vegetable Seed Co., Inc., Santa Maria, CA) and the broccoli cultivar Greenbelt (Rogers Seed Co., Gilroy, CA) were used in all experiments. All plots were planted on raised beds shaped on 1-m centers. Lettuce seeds were directly sown into two rows ( $25 \mathrm{~cm}$ apart) per bed at a rate of $3 \mathrm{~kg} \mathrm{ha}^{-1}$. Immediately after seeding, the herbicide Pronamide (3,5dichloro- $N$ (1,1-dimethyl-2-propynyl) benzamide; Rohm and Haas Company, Philadelphia, PA) at $2.25 \mathrm{~kg} / \mathrm{ha}$ was applied to the lettuce plots and watered in. After emergence, lettuce plants were thinned to $30 \mathrm{~cm}$ between plants. Broccoli was transplanted at a spacing of $15 \mathrm{~cm}$, and the herbicide DCPA (dimethyl tetrachloroterephthalate; AMVAC Chemical Corporation, Los Angeles, CA) was applied at recommended rates for weed control. All plots were fertilized according to best management practices with ammonium nitrate at the rate of $160 \mathrm{~kg}$ of $\mathrm{N} \mathrm{ha}^{-1}$ in banded, split applications. Detailed information on the field and crop management practices is described in Hao et al. (12).

At the Spence site, where there was no history of lettuce drop, all plants were inoculated after the first thinning (June 1995) with two to three rye seeds each infested with $S$. minor (12). Normal tillage operations were employed following harvest at crop maturity. During the subsequent season, three rotation treatments were established: consecutive lettuce crops (LLL); lettuce rotated with broccoli (LBL); and lettuce followed by a fallow cycle (LFL) (12). Treatments were arranged in a randomized complete block design with four replications. Each main treatment plot was 8 beds wide and $12 \mathrm{~m}$ long. Plots were separated by two-bed borders across rows and $6 \mathrm{~m}$ of bare space along the rows to avoid plot crosscontamination. The plots were reworked and beds were shaped for planting of the next crop in each treatment a month after crop incorporation. The fallow plots were maintained and irrigated along with the other treatments, except that no weeding was done during the fallow period. Lettuce crops were planted in June 1995 (inoculated), and subsequently during cropping seasons of spring and fall 1996 and 1997. In the spring seasons of 1996 and 1997, lettuce was planted in treatment LLL, broccoli was planted in treatment LBL, and the plots were left fallow in LFL.

The second experiment, located at the Hartnell College East Campus, had previously been used for other experiments on $S$. minor, and thus sclerotia were initially present in the soil (27). However, to establish a uniform distribution of the inoculum, all plants were inoculated after thinning or transplanting as described above (12). In the fallow treatment, infested rye seeds were pressed into the soil using the same amount of inoculum as in the lettuce and broccoli plots. Treatments at this site included the following crop sequences (12): lettuce-lettuce-lettuce-lettuce (LLLL); broccoli-lettuce-broccoli-lettuce (BLBL); broccoli-broccoli-lettuce-lettuce (BBLL); and fallow-lettuce-fallow-lettuce (FLFL). After harvest, all plants, either lettuce or broccoli, were incorporated into the soil as
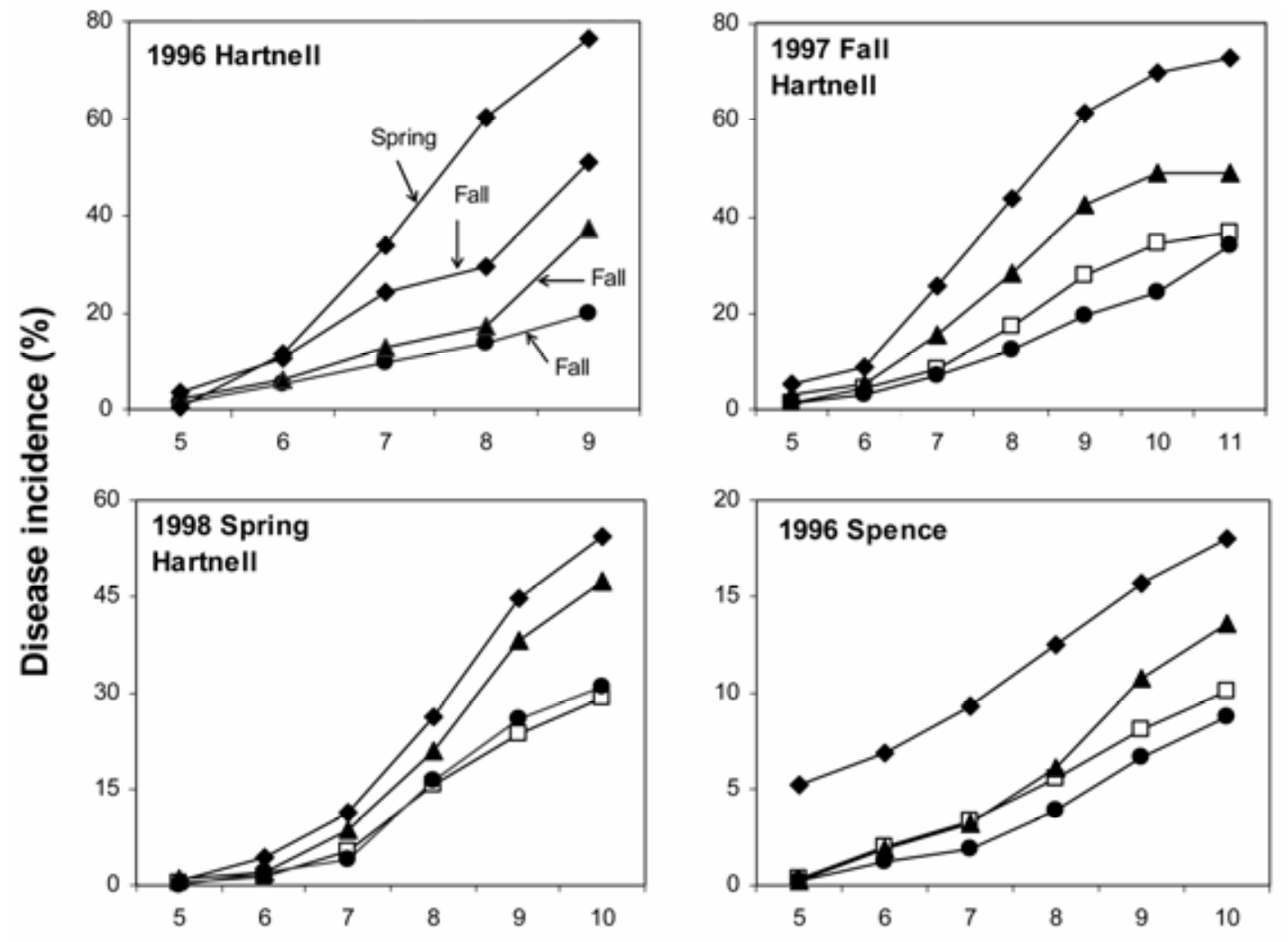

\section{Week from planting}

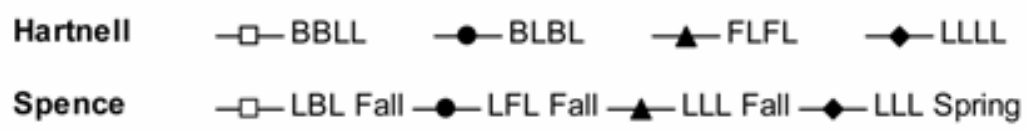

Fig. 1. Disease progress curves for lettuce drop crop rotation treatments at Hartnell College East Campus and Spence field sites during 1996 and 1997. Only the field plots with at least five observation points within one season are shown. Each point is the average of four (Spence) or three (Hartnell) replicated plots. 
described above. Lettuce was planted in the spring of 1996, and subsequent crops were planted during the fall of 1996, fall and spring of 1997, and spring 1998. Plots were 6 beds wide and $20 \mathrm{~m}$ long, and arranged in a randomized complete block design with three replications. Plots were separated by two-bed borders and $10 \mathrm{~m}$ of bare soil between blocks to avoid plot interactions.

Disease incidence and soil sampling. An area of $8 \times 10 \mathrm{~m}$ at Spence and $4 \times 10$ $m$ at Hartnell was demarcated in each plot for data collection. Lettuce drop development in each plot was monitored weekly after thinning. After lettuce drop appeared in any one plot, each plant in the demarcated area was evaluated for the presence or absence of lettuce drop. Each plot was further divided into $1 \times 1 \mathrm{~m}$ quadrats, and disease incidence was calculated for each quadrat.

Two of the three replications at Hartnell and two of the four replications at Spence were used for quadrat-based soil sampling. Soil samples were collected from each quadrat in the middle $6 \times 8 \mathrm{~m}$ area at Spence and $4 \times 6 \mathrm{~m}$ area at Hartnell. At the beginning of each cropping season, 100 $\mathrm{cm}^{3}$ of soil was sampled from each $1 \times 1 \mathrm{~m}$ quadrat. To determine the overall temporal dynamics of pathogen populations, 18 subsamples at Spence and 12 subsamples at Hartnell were randomly collected from each plot at the beginning of each season. Soils were assayed by wet sieving (23),
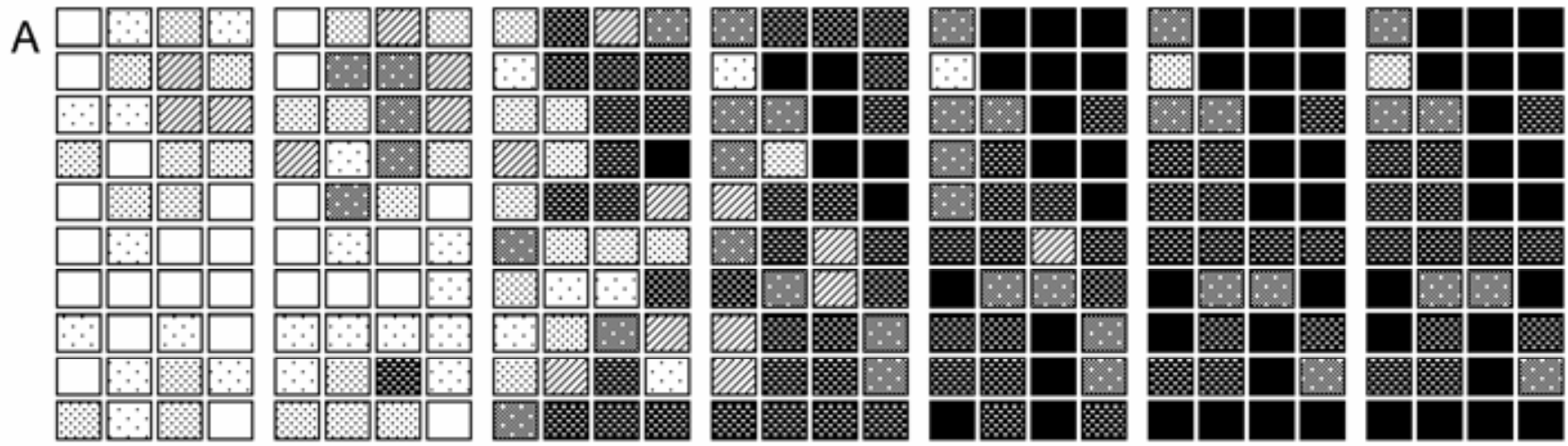

B
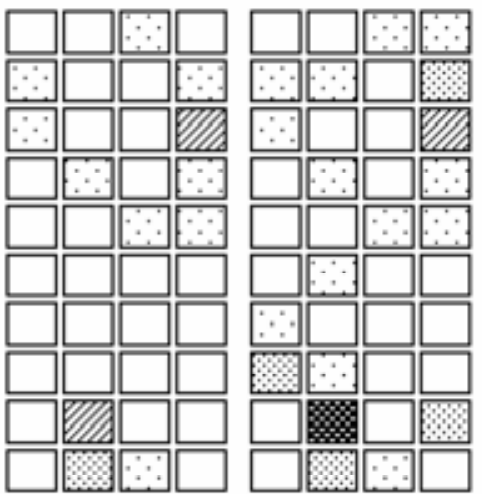

C

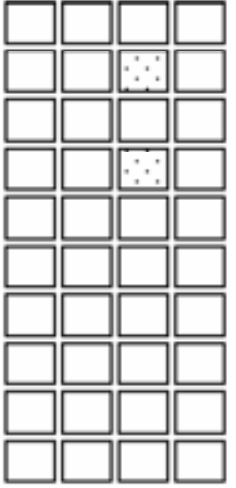

Wk 1

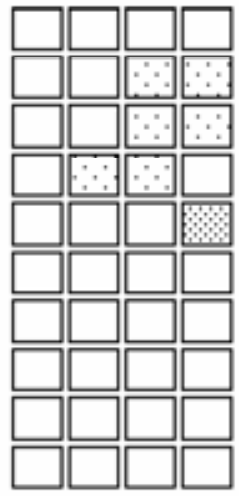

Wk 2
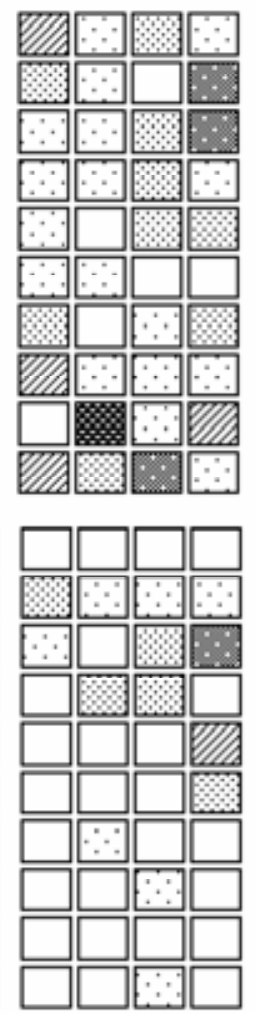

Wk 3
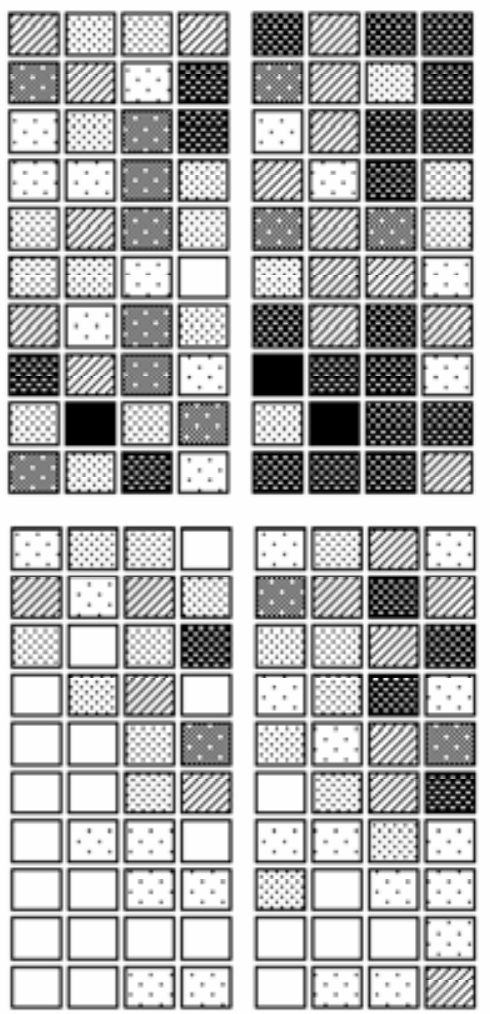

Wk 4

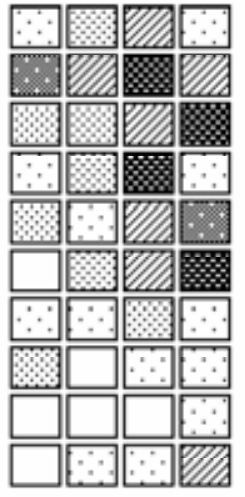

Wk 5
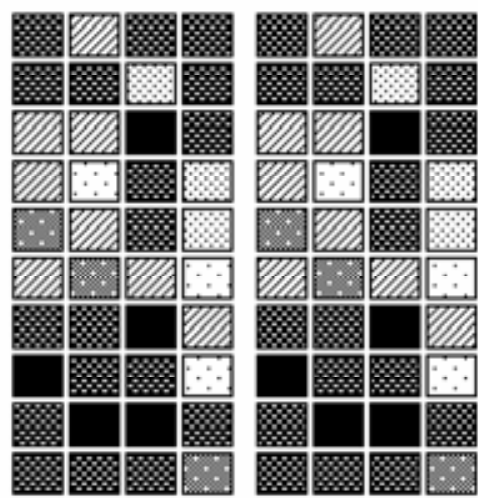

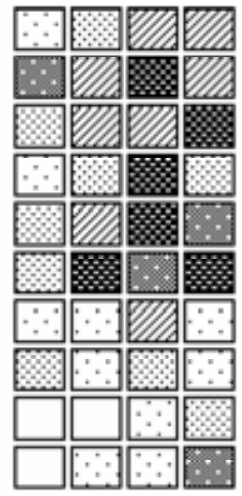

Wk 6

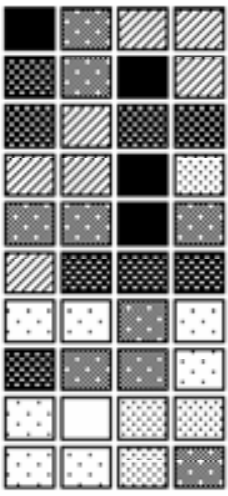

Wk 7

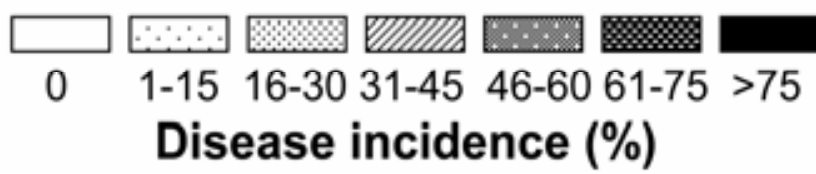

Fig. 2. Weekly distribution of lettuce drop incidence at the Hartnell site in the continuous lettuce (A), fallow-lettuce (B), and broccoli-lettuce (C) treatments within the fall 1997 season. The precise location of each diseased and healthy plant was recorded in the middle $4 \times 10 \mathrm{~m}$ area of the plot. The disease incidence was then calculated for $1 \times 1 \mathrm{~m}$ quadrats. The index of disperson $(D)$ from week 1 to 7 for the continuous lettuce treatment was $1.7,1.62,1.79,1.53$, $1.98,1.97$, and 1.97, respectively; for lettuce-fallow treatment, 1.59, 1.71, 1.36, 1.27, 1.72, 2.04, and 2.04, respectively; and for broccoli-lettuce treatment, $0.9,0.98,1.00,1.01,1.79,1.53$, and 1.47 , respectively. 
and sclerotia were recovered and counted under a stereomicroscope. Viability of sclerotia was tested on water agar plates.

Analyses of lettuce drop incidence in rotation treatments. Disease incidence and sclerotial populations were mapped for each treatment at both locations for visual assessments of changes over time. A computer program DMAP (J. J. Hao and K. V. Subbarao, unpublished) was used to generate population density maps. Multiple methods were employed to analyze the spatial data for disease incidence and sclerotia. The BBD computer software was used for several methods of spatial analyses (15), including a beta-binomial distribution analysis as suggested for binary data such as disease incidence (13). Several parameters were used for measuring dispersion. An index of dispersion $(D)$, defined as the ratio of actual variance to the theoretical variance for a random (binomial) distribution $(13,15)$, and the aggregation index $(\theta)$ of the betabinomial distribution were calculated to measure the degree of aggregation in disease incidence. The spatial distribution is considered uniform when $D=1$, random when $D<1$, and aggregated when $D>1$; a larger $\theta$ and smaller standard error of $\theta$ also indicate an aggregation pattern. When $\theta$ is 0 , the pattern tends to be random. A $t$ test ( $t$ $=\theta / \operatorname{se}(\theta))$ was performed to test significant deviations from $0(13,15)$. Neyman's $C(\alpha)$ test was used to test the significance of over-dispersion for beta-binomial distribution, where $Z$ is the calculated test statistic. A large $Z$ or small $P$ (probability of significance, 0.05 ) in this test means the binomial (random) distribution is rejected in favor of a beta-binomial (aggregated pattern) distribution.

Spatial analyses of inoculum density. The degree of spatial aggregation in sclerotial populations was estimated by calculating the Lloyd's index of patchiness (LIP): $\left[\left(x+s^{2}\right) /(x-1)\right] / x$, where $x$ and $s^{2}$ are the mean and variance for the number of sclerotia per plot. LIP $>1$ indicates aggregation; otherwise it indicates a random or uniform distribution. The numbers of plots with LIP $>1$ and with LIP $\leq 1$ were sorted and compared for each season to determine the seasonal changes in aggregation. LIP (19) was further analyzed by variance analysis or linear regression to determine differences among treatments, seasons, and sites. The SAS mixed model procedure and general regression (REG) procedure were used (SAS version 8.0, SAS Institute, Cary, NC) to determine time effects on the index of dispersion $(D)$, and seasonal changes of sclerotial distribution in soil represented by LIP.

Relationships between inoculum density and disease incidence (ID-DI). Data from both lettuce drop incidence and number of sclerotia from all lettuce plots and all seasons were used in these analyses.
The relationship between disease incidence and sclerotial population was determined by linear regression.

Competence volume of $S$. minor sclerotia. In the greenhouse, 3.8-liter Styrofoam containers were filled with sandy soil, which was previously pasteurized twice for $2 \mathrm{~h}$ at $93^{\circ} \mathrm{C}$. Lettuce seeds (cultivar Salinas, coated, Pybas Seed Company, Santa Maria, CA) were placed in the center of the pots at a depth of $1 \mathrm{~cm}$. At the same time, three sclerotia of $S$. minor were placed in each pot at designated horizontal and vertical distances from the center of the pot. A combination of positions was used, ranging from 0 to $6 \mathrm{~cm}$ (in $1-\mathrm{cm}$ increments) horizontally and 0 to $8 \mathrm{~cm}$ (also in 1-cm increments) vertically. Each pot was placed in a saucer, and three holes were made at the bottom of each pot. Water was supplied to the saucer so that watering did not disturb the position of sclerotia. The plants were incubated on greenhouse benches (under a day/night temperature regime of $22 \pm 3^{\circ} \mathrm{C}$ and $12 \pm$ $2^{\circ} \mathrm{C}$, respectively, with relative humidity in the range of 50 to $70 \%$ ). Each treatment had three replications. Plants were fertilized once every 3 weeks and observed for lettuce drop weekly. The date of lettuce drop symptom onset in each treatment (or pot) was recorded, and the days to symptom development following inoculation were calculated. The experiment was re-

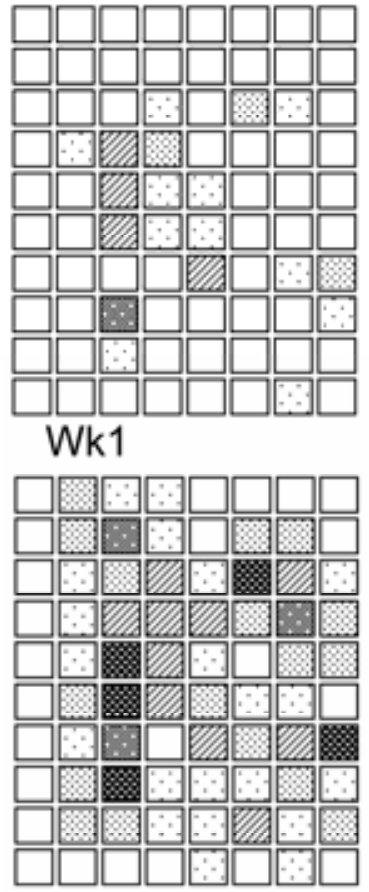

Wk5

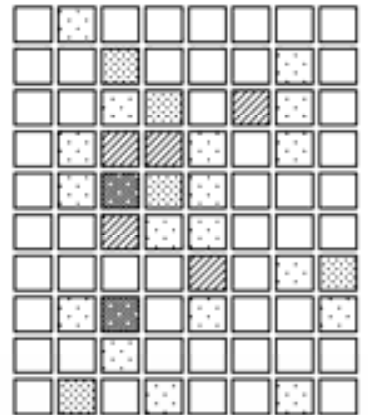

Wk2

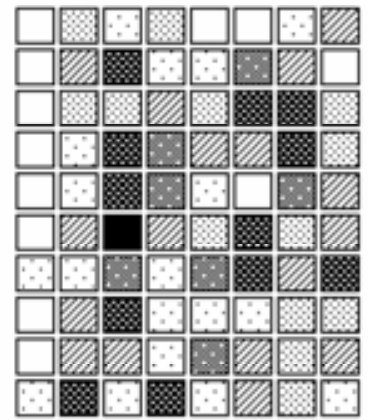

Wk6

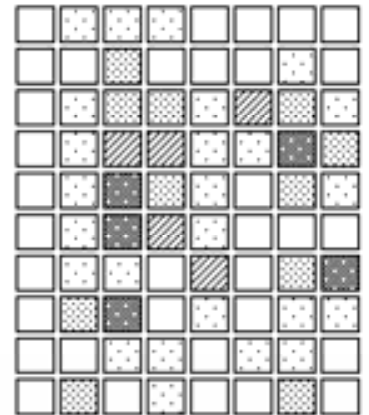

Wk3

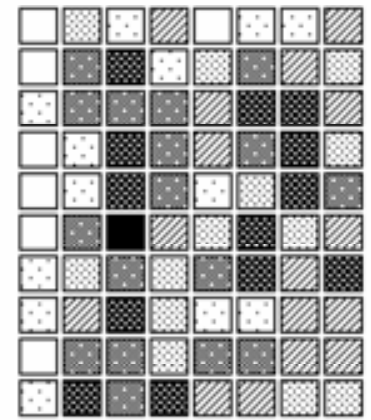

Wk7

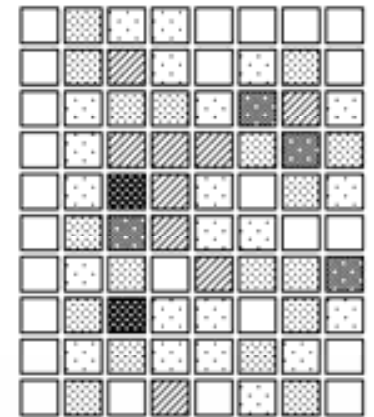

Wk4

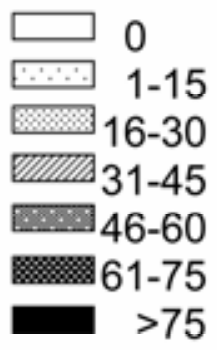

\section{Disease incidence (\%)}

Fig. 3. Weekly distribution of lettuce drop incidence at the Spence site in the continuous lettuce cropping treatment during the 1996 spring season. The precise location of the diseased and healthy plants was recorded in the middle $8 \times 10 \mathrm{~m}$ area of the plot. Disease incidence was then calculated for $1 \times 1 \mathrm{~m}$ quadrats. Numbers below each $4 \times 10$ grid are the weeks after thinning. The index of disperson $(D)$ from week 1 to 7 was $1.89,1.78,1.57,1.54,1.69,2.03$, and 1.96 , respectively. 
peated three times. During the 4-week period of the experiment, the roots in the pots did not expand significantly, so this factor was ignored for its effect on the distance between inoculum and roots. Regression analysis on incidence of lettuce drop and horizontal distance, vertical depth, and absolute distance (calculated as the distance from seed to inoculum) of inoculum was performed using SAS procedures.

\section{RESULTS}

Disease progress. At both Spence and Hartnell, lettuce drop appeared first in continuous lettuce plots (LLL or LLLL), increased rapidly, and reached a maximum

Table 1. Statistics for describing spatial pattern of lettuce drop incidence at Hartnell and Spence field sites between years 1996 and 1998

\begin{tabular}{|c|c|c|c|c|c|c|c|c|c|c|}
\hline Field & Treatment & Season & $D^{\mathbf{a}}$ & $\theta^{\mathbf{b}}$ & $\operatorname{se}(\theta)^{c}$ & $Z^{\mathrm{d}}$ & $P(Z)^{\mathrm{e}}$ & $D^{\mathbf{f}}$ & $P(D)^{\mathrm{g}}$ & $P(\mathbf{B})^{\mathrm{h}}$ \\
\hline \multirow[t]{11}{*}{ Hartnell } & \multirow[t]{4}{*}{ LLLL } & 1996 Spring & $0.910^{\mathrm{i}}$ & 0.040 & 0.049 & 1.451 & 0.073 & 1.18 & 0.216 & 0.534 \\
\hline & & 1997 Spring & 0.322 & 0.000 & -1 & -0.689 & 1.000 & 0.88 & 0.687 & - \\
\hline & & 1997 Fall & 0.771 & 0.192 & $0.085^{*}$ & 4.137 & $<0.001$ & 1.97 & 0.001 & 0.012 \\
\hline & & 1998 Spring & 0.766 & 0.130 & $0.063^{*}$ & 4.137 & $<0.001$ & 1.97 & 0.001 & 0.468 \\
\hline & \multirow[t]{3}{*}{ BBLL } & 1997 Spring & 0.056 & 0 & -1 & -1.995 & 1.000 & 0.60 & 1.000 & - \\
\hline & & 1997 Fall & 0.467 & 0.120 & $0.060 *$ & 3.354 & $<0.001$ & 1.79 & 0.003 & 0.539 \\
\hline & & 1998 Spring & 0.434 & 0.042 & 0.042 & 1.297 & 0.097 & 1.32 & 0.096 & 0.807 \\
\hline & \multirow[t]{2}{*}{ BLBL } & 1997 Fall & 0.266 & 0.136 & $0.065^{*}$ & 4.184 & $<0.001$ & 1.98 & $<0.001$ & 0.228 \\
\hline & & 1998 Spring & 0.163 & 0.072 & 0.056 & 1.650 & 0.049 & 1.4 & 0.053 & 0.145 \\
\hline & \multirow[t]{2}{*}{ FLFL } & 1997 Fall & 0.358 & 0.087 & 0.054 & 2.615 & 0.004 & 1.62 & 0.011 & 0.365 \\
\hline & & 1998 Spring & 0.479 & 0.023 & 0.037 & 0.702 & 0.241 & 1.19 & 0.206 & 0.034 \\
\hline \multirow[t]{8}{*}{ Spence } & \multirow[t]{4}{*}{ LLL } & 1996 Spring & 0.160 & 0.290 & $0.076^{*}$ & 10.430 & $<0.001$ & 2.56 & $<0.001$ & 0.396 \\
\hline & & 1996 Fall & 0.133 & 0.023 & 0.026 & 0.922 & 0.178 & 1.31 & 0.031 & 0.114 \\
\hline & & 1997 Spring & 0.015 & 0.015 & 0.031 & 0.636 & 0.263 & 1.11 & 0.240 & $<0.001$ \\
\hline & & 1997 Fall & 0.080 & 0.013 & 0.024 & 0.681 & 0.248 & 1.02 & 0.440 & $<0.001$ \\
\hline & \multirow[t]{2}{*}{ LBL } & 1996 Fall & 0.111 & 0.032 & 0.028 & 1.276 & 0.101 & 1.20 & 0.105 & 0.238 \\
\hline & & 1997 Fall & 0.091 & 0.101 & $0.047^{*}$ & 4.617 & $<0.001$ & 1.7 & $<0.001$ & 0.371 \\
\hline & \multirow[t]{2}{*}{ LFL } & 1996 Fall & 0.018 & 0.026 & 0.679 & 0.249 & $<0.001$ & 1.11 & 0.228 & $<0.001$ \\
\hline & & 1997 Fall & 0.114 & 0.002 & 0.020 & 0.088 & 0.465 & 1.03 & 0.416 & $<0.001$ \\
\hline
\end{tabular}

a Mean disease incidence, expressed as percentage of diseased plants out of total plants in the plot.

b Aggregation index.

c Standard error of the mean $\theta$. "*" indicates an aggregated pattern according to a $t$ test.

d Statistic of the $\mathrm{C}(\alpha)$ test.

e Probability associated $Z$ at significance level $(\alpha)=0.05$.

${ }^{\mathrm{f}}$ Index of dispersion.

g Probability associated with $D$ at significance level $(\alpha)=0.05$.

${ }^{\mathrm{h}}$ Used for beta-binomial distribution goodness-of-fit analysis. $P_{b}=$ Probability of rejecting the null hypothesis that the data fit the beta-binomial distribution.

i Lettuce drop incidence data were analyzed only for seasons with lettuce in all plots. Incidence was evaluated before crop harvest. "_" indicates the result was not generated due to insufficient data.

A

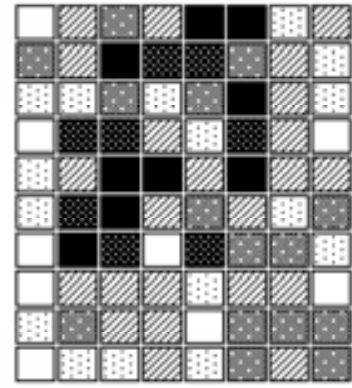

B

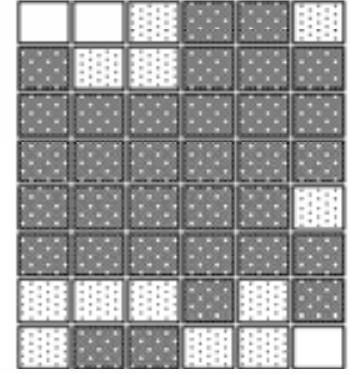

1996 spring
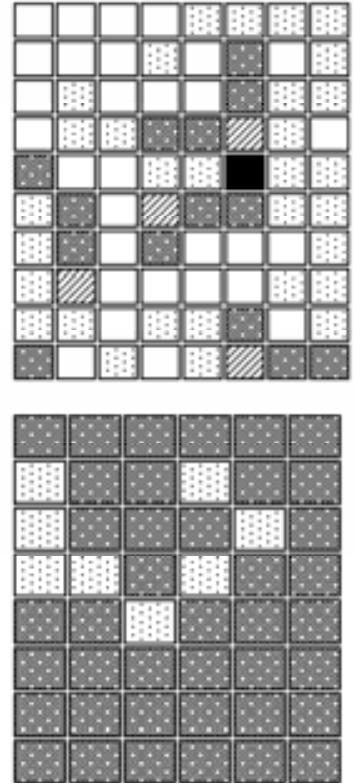

1996 fall
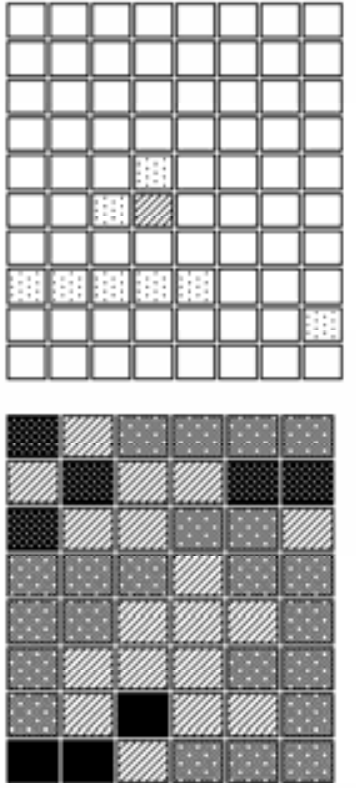

1997 spring
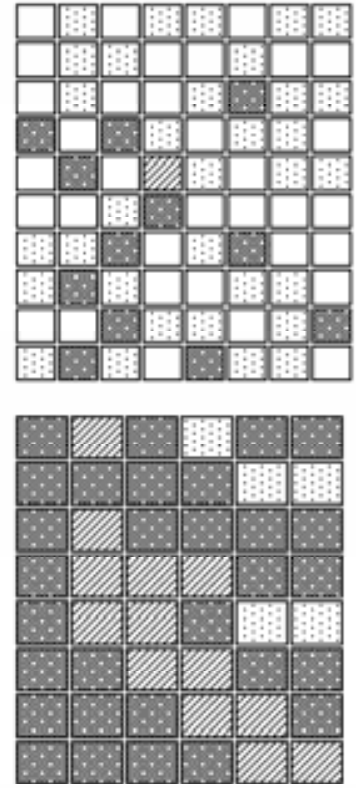

1997 fall
A: Disease incidence (\%)

B: Sclerotia per $100 \mathrm{~cm}^{3}$ soil

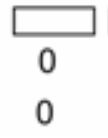

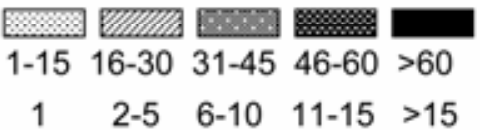

Fig. 4. Spatial pattern of incidence of lettuce drop (A) and corresponding sclerotial density (B) at the beginning of four cropping seasons observed at the end of each season at Spence following inoculation in fall of 1995. Each cell of the map represents a $1 \times 1 \mathrm{~m}$ quadrat. Data presented are for the continuous lettuce cropping treatment in one plot (LLL, replication 2). The $D$ value for disease incidence was $1.64,1.18,1.30$, and 10.88, respectively, and the LIP for sclerotial distribution was $0.83,0.80,1.56$, and 0.97 . 
by the end of the season (Figs. 1 and 2). Final lettuce drop incidence in continuous lettuce plots at Hartnell varied from 50 to nearly $80 \%$ during the different seasons of the study (Figs. 1 and 2A), with the highest incidence recorded in spring 1996 when all of the plants were inoculated after thinning. Plots rotated with broccoli (LBL, BLBL, and BBLL) showed delayed appearance of lettuce drop and had the lowest final disease rating (Figs. 1 and 2C). Lettuce drop incidence in fallow plots was intermediate (Figs. 1 and 2B). The trends were similar at the Spence site (Fig. 1). However, incidence of lettuce drop at this location was lower than at Hartnell during all seasons (data from only one season shown for the Spence site) (Figs. 2 and 3).
Patterns of lettuce drop incidence. At both sites, no disease was observed on broccoli either within a season or over the duration of the experiment. At Spence, disease incidence in LLL was aggregated in spring 1996, the first season after inoculation of all plants at thinning. The patterns were less aggregated during the following seasons as a result of low incidence of lettuce drop. At this site, only $16 \%$ of the plots showed aggregation in 1996 and 1997 fall. A majority of the plots exhibited spatially random disease incidence (Table 1, Fig. 4). Crop rotation treatments did not affect the spatial patterns at the Hartnell site, but seasons and time of disease evaluation did (Table 2).

At Hartnell, each plant was inoculated in spring 1996. Incidence of lettuce drop

Table 2. Analysis of variance of treatment effects and time of disease evaluation on index of dispersion $(D)$

\begin{tabular}{llccrc}
\hline Field site & Effect & $\mathbf{d f}_{\mathbf{n}} \mathbf{a}^{\mathbf{a}}$ & $\mathbf{d f}_{\mathbf{d}} \mathbf{b}$ & $\boldsymbol{F}$ & $\boldsymbol{P}^{\mathbf{b}} \boldsymbol{F}^{\mathbf{c}}$ \\
\hline Hartnell & Season & 2 & 149 & 24.82 & $<0.0001^{\text {d }}$ \\
& Treatment & 3 & 149 & 6.64 & 0.0008 \\
& Season $\times$ treatment & 6 & 149 & 2.72 & 0.0450 \\
Spence & Season & 3 & 161 & 57.05 & $<0.0001$ \\
& Treatment & 2 & 161 & 0.31 & 0.8276 \\
& Season $\times$ treatment & 6 & 161 & 3.51 & 0.0322 \\
\hline
\end{tabular}

a Numerator degrees of freedom.

b Denominator degrees of freedom.

c Probability associated with $F$ value.

${ }^{\mathrm{d}}$ In this case, each plot was calculated for $D$ using BBD program, and the $D$ was further analyzed by SAS program. Lettuce drop incidence data were analyzed only for seasons with lettuce in all plots.

A
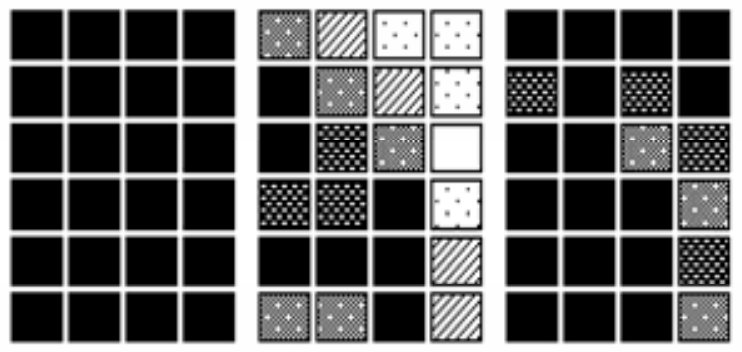

B

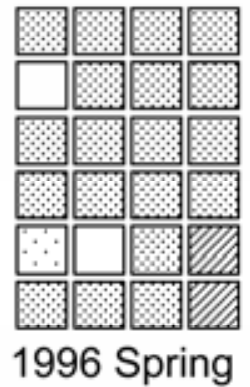

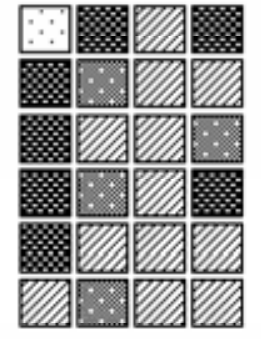

1997 Spring

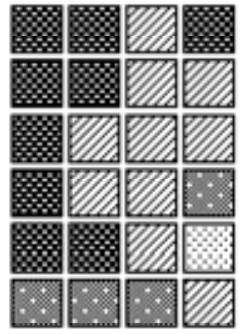

1997 Fall was close to $80 \%$ in the continuous lettuce treatment, and the distribution of the disease was nearly uniform. Incidence of lettuce drop in 1997 fall, when all plots had lettuce, was random during the first week after thinning for all plots (Fig. 2). Incidence of lettuce drop in the continuous lettuce treatment became aggregated beginning the second week after thinning (Fig. 2). In contrast, disease incidence in the fallow-lettuce treatment became aggregated at week 3 , and in the broccoli-lettuce treatment, the disease remained random until 3 weeks prior to the end of season (Fig. 2). The distribution of the disease was similar in all replicated plots within each treatment as confirmed by statistics $\theta$, $Z$, and goodness-of-fit analysis (Table 1). Disease incidence was randomly distributed at the beginning of the experiment in 1996 spring for the continuous lettuce treatment, and changed to aggregated patterns in 1997 fall and 1998 spring. Following an aggregated pattern in 1997 fall, spatial arrangements of diseased plants in BLBL, BBLL, and FLFL were mostly random (Table 1). At Spence, lettuce drop incidence had aggregated patterns throughout the season (Fig. 3). Disease distribution was aggregated in plots with high disease incidence (Table 1). Disease incidence and spatial distribution of disease approximated the distribution and density of sclerotia in soil at Hartnell (Fig. $5)$. For example, in one plot with continu-
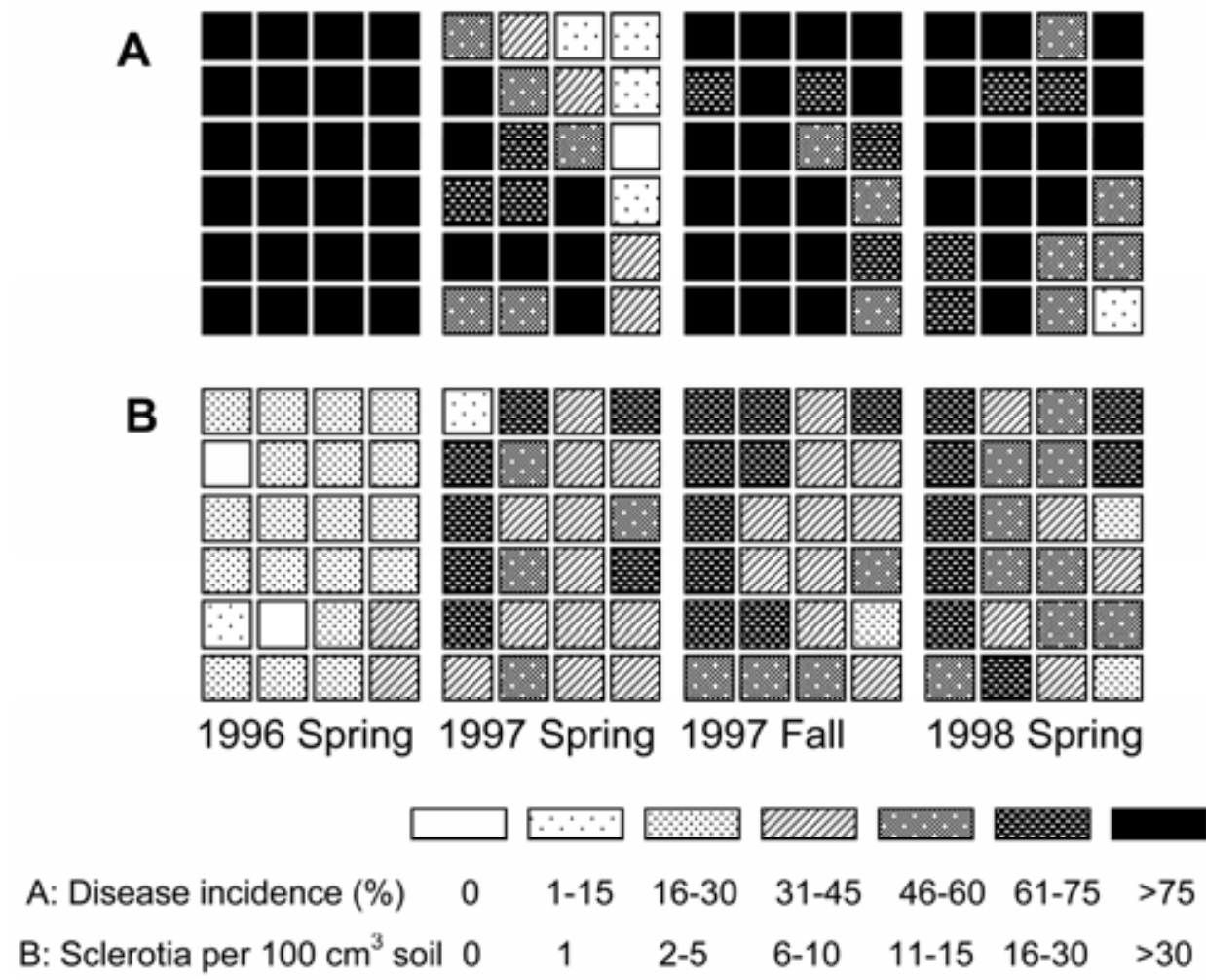

Fig. 5. Spatial distribution of sclerotial density and corresponding incidence of lettuce drop at Hartnell following inoculation in spring 1996. The upper four maps (A) are disease distribution maps representing four cropping seasons. The index of disperson $(D)$ from the first to last season was $1.01,1.17,1.56$, and 0.98. The lower four maps (B) display sclerotial distribution during the corresponding seasons. The LIP from the first to last season was $1.10,1.17,1.15$, and 1.03, respectively. Each cell of the map represents a $1 \times 1 \mathrm{~m}$ quadrat. Data presented are for the continuous lettuce cropping treatment in one plot (LLLL, replication 3 ). 
ous lettuce treatment, disease incidence and inoculum were randomly distributed initially but became aggregated when the inoculum distribution was also aggregated (Fig. 5). Similar patterns were also observed in other treatments (data not shown). At Spence, a similar relationship was detected, although there were a few exceptions (Fig. 4).

Spatial analyses of sclerotial populations. The average of sclerotial viability was $70 \%$. At the Spence site, both the density of sclerotia and the degree of aggregation changed over time after the lettuce crops (Fig. 4). The changes in the degree of aggregation were significant between seasons but not between treatments according to the Lloyd's index of patchiness (Table 3). The sclerotial distribution was random in 1996 spring and fall, and became aggregated in 1997 spring (Table 4). However, the pattern was random again in 1997 fall.

At Hartnell, sclerotial density increased as the number of lettuce crops increased (Fig. 6). For example, numbers of sclerotia in the continuous lettuce treatment increased and the spatial pattern changed from random to aggregated over several seasons (Fig. 6A). The sclerotial densities were lower in the fallow-lettuce treatment (FLFL) as well as lettuce alternated with broccoli (BLBL), and spatial patterns were almost random in most seasons (Fig. 6B). In both LLLL and FLFL, the inoculum density in soil samples collected at the end of the cropping season was higher than in

Table 3. Effects of season and treatment on Lloyd's index of patchiness of sclerotial distribution

\begin{tabular}{llcccc}
\hline Location & Source & $\mathbf{d f}_{\mathbf{n}} \mathbf{a}^{\mathbf{a}}$ & $\mathbf{d f}_{\mathbf{d}} \mathbf{b}$ & $\boldsymbol{F}$ & $\boldsymbol{P}>\boldsymbol{F}^{\mathbf{c}}$ \\
\hline Hartnell & Season & 4 & 8 & 1.65 & 0.2577 \\
& Treatment & 3 & 6 & 1.48 & 0.3028 \\
& Season $\times$ treatment & 12 & 8 & 1.43 & 0.3129 \\
Spence & Season & 3 & 6 & 6.00 & 0.0373 \\
& Treatment & 2 & 1 & 0.09 & 0.7866 \\
& Season $\times$ treatment & 6 & 0 & 0.16 & \\
\hline
\end{tabular}

a Numerator degrees of freedom.

${ }^{\mathrm{b}}$ Denominator degrees of freedom.

${ }^{c}$ probability associated with $F$ value.

corresponding samples collected at thinning of the subsequent crop in all seasons except in 1997 spring (Fig. 6A and B). In contrast, inoculum density remained consistently lower in plots rotated with broccoli (BLBL or BBLL); the numbers of sclerotia at thinning and at the end of the broccoli season did not vary significantly, and the distribution of sclerotia was nearly random (Table 4 and Fig. 6C). The Lloyd's index of patchiness showed that the number of plots exhibiting aggregation of sclerotia was highest at the end of the season and the number of plots exhibiting aggregation tended to be lower following tillage treatments after a crop (Table 4). In 1996 fall and 1997 spring, six out of nine plots exhibited aggregation at the beginning of a season, but all were aggregated by the end of the season (just before harvest) (Table $4)$. Plots in which sclerotia were aggregated at the beginning of the experiment continued to show aggregation over time with the number of plots with aggregated sclerotia fluctuating between six and seven out of nine (Table 4).

Relationship of inoculum density and disease incidence (ID-DI). The incidence of lettuce drop was positively correlated to the number of sclerotia per $100 \mathrm{~cm}^{3}$ of soil sampled at the beginning of the sea-
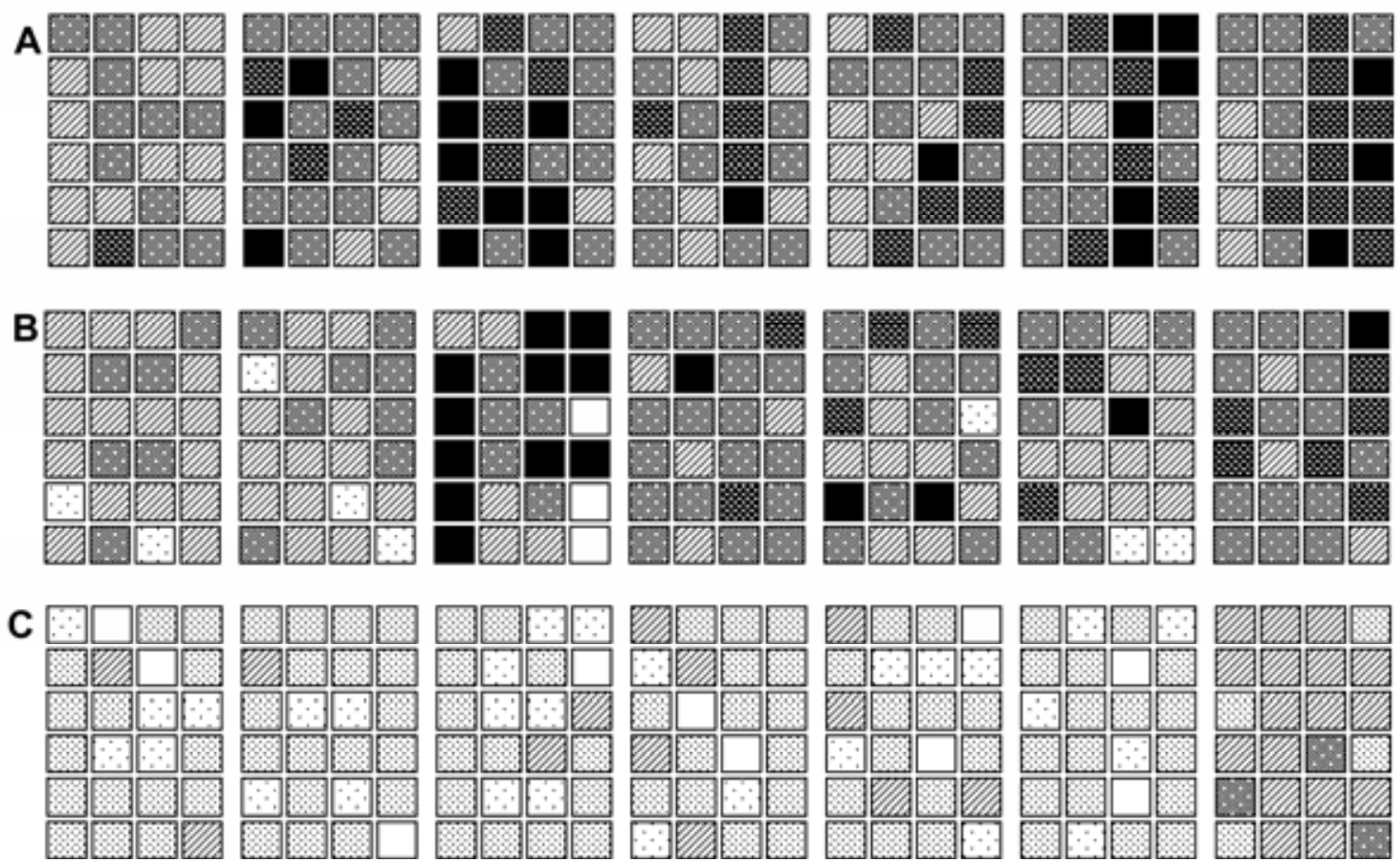

I

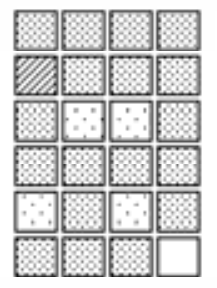

$\mathrm{II}_{\mathrm{b}}$
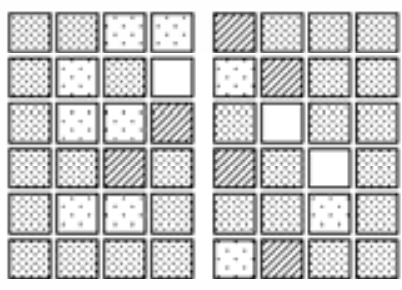

$\mathrm{II}_{\mathrm{e}}$

$\mathrm{III}_{\mathrm{b}}$

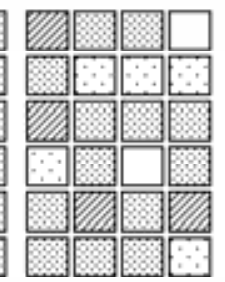

$\mathrm{III}_{\mathrm{e}}$

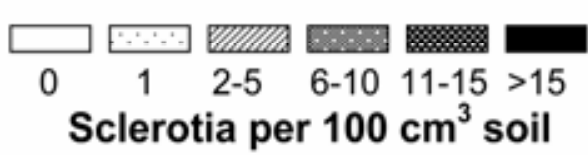

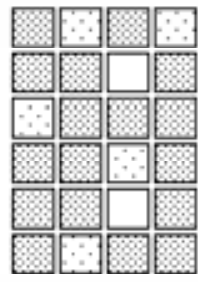

IV

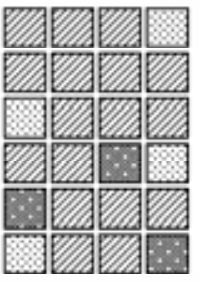

V

Fig. 6. Spatial patterns of Sclerotinia minor sclerotia at Hartnell in different crop rotation treatments during seven sampling times between 1996 and 1998. The dynamics of sclerotia are illustrated for continuous lettuce (A), lettuce alternated with fallow (B), and lettuce alternated with broccoli treatments (C).

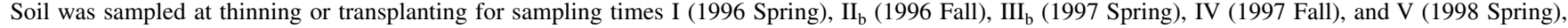
and for $\mathrm{II}_{\mathrm{e}}\left(1996 \mathrm{Fall}_{\text {) }}\right.$ and $\mathrm{III}_{\mathrm{e}}$ (1997 Spring) at the end of the season. The LIP and the beginning of the season was 1.00, 1.13, 1.23, 2.18, and 1.04 for LLLL; $0.99,1.06,1.07,1.31$, and 0.99 for FLFL; and 1.05, 0.92, 1.31, 0.90, and 0.97 for BLBL, respectively. 
son at Hartnell, regardless of the season or treatment. The increase in lettuce drop incidence was linear, and the coefficient of determination $\left(R^{2}\right)$ was $0.53(P=$ 0.001). At the Spence site, the ID-DI relationship was also linear during 1996 fall with $R^{2}=0.53(P=0.001)$, when the density of sclerotia was low. There was little correspondence between the numbers of sclerotia in soil and lettuce drop incidence during subsequent seasons at this site (Fig. 7). The high values for the intercepts of the regressions suggested that the variation was big or larger volumes of soil need to be sampled to detect low inoculum densities.

Competence volume of $S$. minor sclerotia. The horizontal position of sclerotia significantly affected the time when infection occurred, but the vertical position did not (Table 5). Sclerotia located closer to the plants caused rapid infection of lettuce. As the distance between sclerotia and lettuce plant increased, not only was symp-

Table 4. Numbers of plots in the rotation study at the two locations in which Lloyd's index of patchiness (LIP) for numbers of sclerotia was more than 1 or was 1 or less than 1 during the different cropping seasons

\begin{tabular}{|c|c|c|c|c|c|c|}
\hline \multirow[b]{2}{*}{ Seasons $^{a}$} & \multicolumn{3}{|c|}{ Hartnell } & \multicolumn{3}{|c|}{ Spence } \\
\hline & Total plots & $\operatorname{LIP}^{\mathbf{b}}>\mathbf{1}$ & LIP $\leq 1$ & Total plots & LIP $>1$ & $\mathrm{LIP} \leq 1$ \\
\hline 1996 Spring & 9 & 7 & 2 & 4 & 0 & 4 \\
\hline 1996 Fall & 9 & 6 & 3 & 7 & 0 & 7 \\
\hline 1996 Fall, EOS & 9 & 9 & 0 & $-^{c}$ & - & - \\
\hline 1997 Spring & 9 & 6 & 3 & 7 & 7 & 0 \\
\hline 1997 Spring, EOS & 9 & 9 & 0 & - & - & - \\
\hline 1997 Fall & 9 & 7 & 2 & 7 & 1 & 6 \\
\hline 1998 Spring & 12 & 10 & 2 & - & - & - \\
\hline
\end{tabular}

${ }^{\mathrm{a}} \mathrm{EOS}=$ end of season. The rest of the sampling time was at the beginning of the season.

${ }^{b}$ An LIP $>1$ indicates aggregated and LIP $\leq 1$ indicates nonaggregated patterns. All plots with an LIP $\leq 1$ at the Hartnell site were from the broccoli-lettuce treatment.

${ }^{c}$ Data were unavailable.

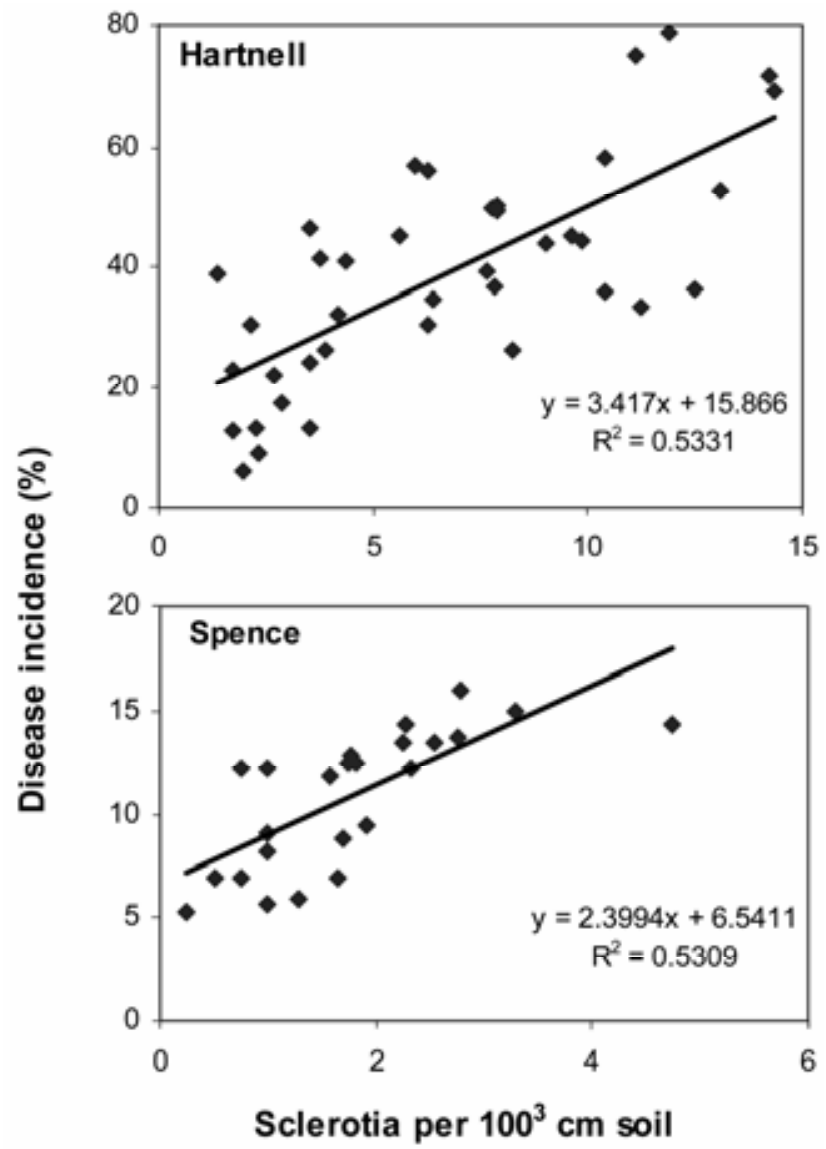

Fig. 7. Relationships between density of Sclerotinia minor sclerotia and lettuce drop incidence at the high inoculum density Hartnell site and the low inoculum density Spence field site. In the linear regression equations, $Y$ represents disease incidence, $X$ represents inoculum density as number of sclerotia per $100 \mathrm{~cm}^{3}$ soil. tom onset delayed but disease incidence was lowered (Fig. 8). Regardless of the horizontal or vertical location of sclerotia, the infection was negatively correlated with the absolute distance $\left(R^{2}=0.67\right.$ and $P$ $=0.0001)$. Sclerotia located closer to the lettuce crown caused a greater number of infections than did more distant sclerotia. Sclerotia within $2 \mathrm{~cm}$ of the lettuce root or crown resulted in certain infection of plants, while the incidence progressively decreased with distance and depth of location of sclerotia from plants; sclerotia located $8 \mathrm{~cm}$ away rarely caused infection.

\section{DISCUSSION}

This study demonstrated how cropping sequences at two different sites altered the inoculum density and distribution of $S$. minor sclerotia in soil and how this in turn influenced the patterns of disease incidence in the corresponding rotation treatments. The benefits of rotation with broccoli were more evident at a site with high inoculum density than with low inoculum density. Broccoli rotations were associated with significant decreases in the total inoculum recorded from these plots, relative stability in sclerotial distribution between seasons, and the significantly lower disease incidence on subsequent lettuce crops.

Spatial patterns of disease reflected the pattern of sclerotial distribution in the soil at high inoculum density. Aggregated sclerotial distribution resulted in an aggregated disease pattern. At low inoculum density, this correlation was poor in most seasons as explained by the ID-DI relationship and competence volume results from this study.

Populations of $S$. minor sclerotia varied over time depending on the cropping sequences regardless of initial densities. Sclerotial density greatly increased after consecutive lettuce crops in fields with both high and low initial inoculum density. Populations of sclerotia remained the same in plots left fallow or decreased in plots rotated with broccoli. When lettuce crops were planted, densities of sclerotia increased at harvest compared with the densities posttillage at the beginning of the following crop, but no such inoculum fluctuations were observed when broccoli was planted. The rate of lettuce drop progress was affected by seasons at both locations, suggesting the role of weather on the rate of lettuce drop development. Broccoli crops influenced the level of lettuce drop primarily by reducing inoculum densities in subsequent rotation treatments (12).

Spatial distribution of sclerotia of $S$. minor changed seasonally, depending on the cropping sequence. Under consecutive lettuce cropping, a progressively aggregated spatial pattern of sclerotial distribution developed. Addition of inoculum in high numbers after each lettuce crop was followed by redistribution of sclerotia from tillage, and over time, inoculum density 
increased and sclerotial populations became more aggregated. This is consistent with the results derived from studies in commercial fields of lettuce $(10,16)$ and cauliflower (28). In the FLFL treatment, the distribution of sclerotia tended to be aggregated following the lettuce crop and less aggregated or random when plots were left fallow. Tillage operations normal for the crop were continued during fallow seasons. The increased soil mixing due to tillage operations perhaps increased the likelihood of sclerotia getting rearranged to a greater degree than in other treatments. The pattern of sclerotia in plots rotated with broccoli seldom deviated from random even after multiple lettuce crops. The slight increases in numbers of sclerotia during the lettuce crop were offset by the significant reductions in number of sclerotia after broccoli rotation. Despite tillage operations similar to other treatments, the numbers of sclerotia in soil remained stable with a predictable spatial arrangement. Over time, rotations with broccoli have the potential to reduce the number of sclerotia in soil to a degree that the distribution of sclerotia is no longer affected by tillage practices.

Inoculum densities at the beginning of the following season in all likelihood were affected by factors such as the augmentation/attrition of inoculum during the previous season and tillage operations after the previous crop. This was evidenced by the greater aggregation of sclerotia at the end of the season than at the beginning at Hartnell. At the end of the season, sampling accounted for part of the inoculum added during the season and their spatial arrangement, and the effects of postcrop tillage practices accounted for the spatial

Table 5. Variance analysis on the effect of sclerotial position in pots on infection of lettuce plants by Sclerotinia minor in the greenhouse

\begin{tabular}{llcccc}
\hline Measurement $^{\mathbf{a}}$ & Location of sclerotia $^{\mathbf{b}}$ & $\mathbf{d f}_{\mathbf{n}} \mathbf{c}$ & $\mathbf{d f}_{\mathbf{d}} \mathbf{d}^{\mathbf{c}}$ & $\boldsymbol{F}$ & $\boldsymbol{P}>\boldsymbol{F}^{\mathbf{e}}$ \\
\hline Time & Horizontal (H) & 6 & 31 & 4.91 & 0.0012 \\
& Vertical (V) & 8 & 31 & 1.64 & 0.0873 \\
Disease & $\mathrm{H}^{*} \mathrm{~V}$ & 28 & 31 & 0.66 & 0.8423 \\
incidence & Horizontal (H) & 6 & 56 & 4.30 & 0.0012 \\
& Vertical (V) & 8 & 56 & 2.90 & 0.0090 \\
& $\mathrm{H}^{*} \mathrm{~V}$ & 28 & 56 & 0.41 & 0.9940 \\
\hline
\end{tabular}

a Time is the period from inoculation to infection, and probability is the average probability of a plant being diseased from a sclerotium located at a certain distance.

${ }^{\mathrm{b}}$ Distance from the center of the pots in horizontal and vertical directions where sclerotia were placed.

$\mathrm{c}$ Numerator degrees of freedom.

${ }^{\mathrm{d}}$ Denominator degrees of freedom.

e Probability associated with $F$ value.

arrangement of sclerotia at the beginning of the season.

Tillage, such as disking (2) and plowing (27), affects sclerotial distribution both horizontally and vertically. The effects of these operations are more pronounced when the inoculum density is higher, resulting in perceptible changes. A single $S$. minor-infected lettuce plant could account for nearly 4,450 sclerotia added to the soil (2). When the crop is incorporated, this can result in an aggregated distribution of sclerotia immediately following harvest. However, the additional tillage treatments required to prepare land for the following planting can redistribute this inoculum both horizontally and vertically, resulting in the dilution of inoculum density. This reduced density of inoculum coupled with altered distribution of sclerotia contributes to lowering of the aggregation of inoculum.

This study was the first to experimentally characterize the competence volume $(7,9)$ of $S$. minor on lettuce. Even though the sclerotia of $S$. minor can germinate eruptively and produce massive amounts of mycelia, there appears to be a limitation on the extent of mycelial growth before infecting a host. The percentage of plants infected by sclerotia declined as the distance to the taproot increased. The maximum distance causing infection was $8 \mathrm{~cm}$, which was longer than that of Sclerotinia rolfsii on carrots (20). When the inoculum density in soil is low, the probability of a sclerotium being located closer to the lettuce plant is also expected to be low, and
Horizontal distance $(\mathrm{cm})$

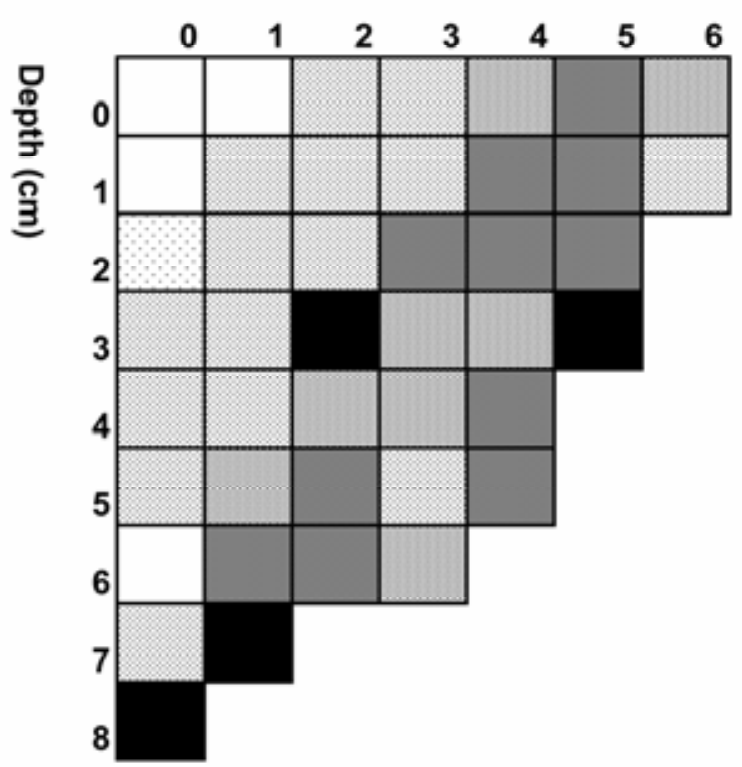

Horizontal distance $(\mathrm{cm})$

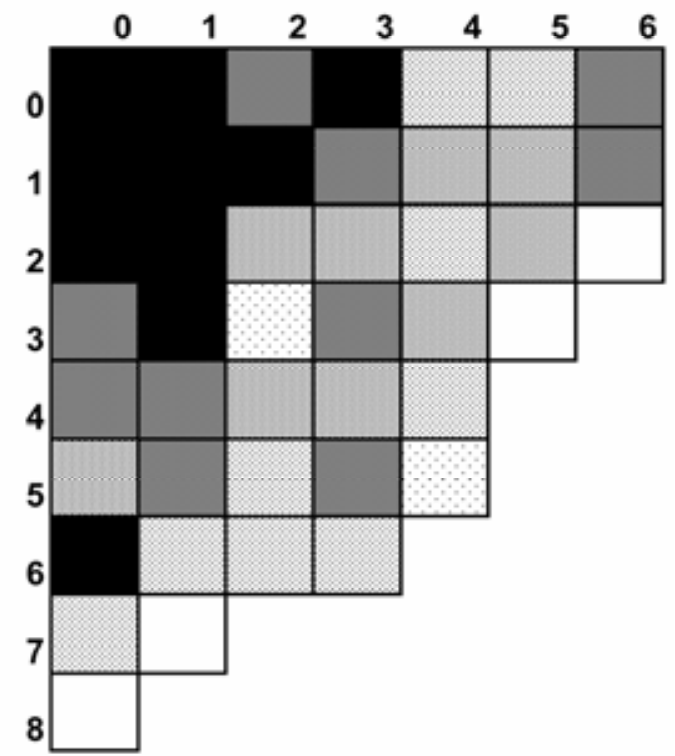

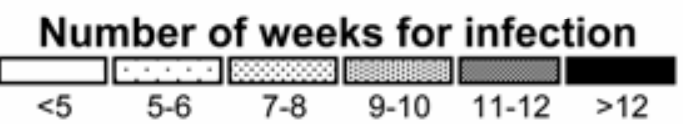

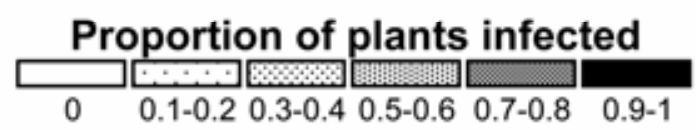

Fig. 8. Relationship between the distance at which sclerotia of Sclerotinia minor were placed from the center of the pot in both horizontal and vertical directions, and the proportion of a lettuce plant being infected. Distance was the length from seed to inoculum, calculated using horizontal and vertical distances. 
thus lowering the mean infection efficiency of the population. Considering the volume around the taproot of lettuce as a cone for the convenience of calculation, the competence volume of an $S$. minor sclerotium was calculated to be $25 \mathrm{~cm}^{3}$ for $100 \%$ infection and $200 \mathrm{~cm}^{3}$ for $50 \%$ infection. Therefore, in $100 \mathrm{~cm}^{3}$ of soil, at least four to five sclerotia are needed for $100 \%$ probability of infection. This is in agreement with the theoretical competence volume calculated for $S$. minor previously $(7,9)$ and provides the first experimental evidence for the concept in this pathosystem. This also explains why there is a high correlation between inoculum density and disease incidence.

In conclusion, the populations of $\mathrm{S}$. $\mathrm{mi}$ nor sclerotia were regulated in soil by the cropping sequences tested in this study. Despite the uniform initial inoculum distribution patterns, augmentation of soil inoculum by continuous lettuce planting led to progressive aggregation of inoculum. In contrast, rotations that led to the attrition of inoculum did not alter the distribution patterns of inoculum despite the tillage treatments. The spatial distribution of lettuce drop incidence invariably reflected the distribution of $S$. minor sclerotia. The determination of the competence volume of $S$. minor sclerotia in this study offered a reasonable explanation for the correlation between high inoculum density and high disease incidence. These results have significant implications for drop management in lettuce production. The primary goal of any lettuce drop management program should be a sustained reduction in the number of $S$. minor sclerotia in soil. This not only lowers losses from lettuce drop but also keeps disease levels predictable in time and space. Rotation with broccoli indeed serves as an important component in the integrated drop management in lettuce.

\section{ACKNOWLEDGMENTS}

We thank the California Lettuce Research Advisory Board for providing funding in support of these studies. We also acknowledge the assistance of Mary Orozco, Judy Hubbard, Steve Koike, and Sharon Benzen during the course of these studies.

\section{LITERATURE CITED}

1. Abawi, G. S., and Grogan, R. G. 1979. Epidemiology of diseases caused by Sclerotinia species. Phytopathology 69:899-904.

2. Adams, P. B. 1986. Production of sclerotia of Sclerotinia minor on lettuce and their distribution in soil after disking. Plant Dis. 70:10431046.

3. Adams, P. B. 1990. The potential of mycoparasites for biological control of plant diseases. Annu. Rev. Phytopathol. 28:59-72.

4. Adams, P. B., and Wong, J. A.-L. 1991. The effect of chemical pesticides on the infection of sclerotia of Sclerotinia minor by the biocontrol agent Sporidesmium sclerotiorum. Phytopathology 81:1340-1343.

5. Campbell, C. L., and Madden, L. V. 1990. Introduction to Plant Disease Epidemiology. John Wiley \& Sons, New York.

6. Davies, J. M. L. 1991. Sclerotinia on peas: Implications for yield and crop rotation. Asp. Appl. Biol. 27:351-354.

7. Dillard, H. R., and Grogan, R. G. 1985. Relationship between sclerotial spatial pattern and density of Sclerotinia minor and the incidence of lettuce drop. Phytopathology 75:90-94.

8. Gilligan, C. A., and Bailey, D. J. 1997. Components of pathozone behavior. New Phytol. 136:343-358.

9. Grogan, R. G., Sall, M. A., and Punja, Z. K. 1980. Concepts for modeling root infection by soilborne fungi. Phytopathology 70:361-363.

10. Hao, J. J., and Subbarao, K. V. 2005. Comparative analyses of lettuce drop epidemics caused by Sclerotinia minor and S. sclerotiorum. Plant Dis. 89:717-725.

11. Hao, J. J., Subbarao, K. V., and Duniway, J. M. 2003. Germination of Sclerotinia minor and $S$. sclerotiorum sclerotia under various soil moisture and temperature combinations. Phytopathology 93:443-450.

12. Hao, J. J., Subbarao, K. V., and Koike, S. T. 2003. Effects of broccoli rotation on lettuce drop caused by Sclerotinia minor and on the sclerotial population in soil. Plant Dis. 87:159166.

13. Hughes, G., and Madden, L. V. 1993. Using the beta-binomial distribution to describe aggregated patterns of disease incidence. Phytopathology 83:759-763.

14. Imolehin, E. D., and Grogan, R. G. 1980. Factors affecting survival of sclerotia, and effects of inoculum density, relative position, and distance of sclerotia from the host on infection of lettuce by Sclerotinia minor. Phytopathology 70:1162-1167.

15. Madden, L. V., and Hughes, G. 1994. BBD-
Computer software for fitting the betabinomial distribution to disease incidence data. Plant Dis. 78:536-540.

16. Marois, J. J., and Adams, P. B. 1985. Frequency distribution analyses of lettuce drop caused by Sclerotinia minor. Phytopathology 75:957-961.

17. Mayton, H. S., Olivier, C., Vaughn, S. F., and Loria, R. 1996. Correlation of fungicidal activity of Brassica species with allyl isothiocyanate production in macerated leaf tissue. Phytopathology 86:267-271.

18. Melzer, M. S., and Boland, G. J. 1994. Epidemiology of lettuce drop caused by Sclerotinia minor. Can. J. Plant Pathol. 16:170-176.

19. Pielou, E. C. 1977. Mathemetical Ecology. John Wiley \& Sons, New York.

20. Punja, Z. K. 1986. Relationships among soil depth, soil texture, and inoculum placement in infection of carrot roots by eruptively germinating sclerotia of Sclerotium rolfsii. Phytopathology 76:976-980.

21. Steadman, J. R. 1979. Control of plant diseases caused by Sclerotinia species. Phytopathology 69:904-907.

22. Subbarao, K. V. 1998. Progress toward integrated management of lettuce drop. Plant Dis. 82:1068-1078.

23. Subbarao, K. V., Dacuyan, S., Koike, S. T., and Jackson, L. E. 1994. Evaluation of three quantitative assays for Sclerotinia minor. Phytopathology 84:1471-1475.

24. Subbarao, K. V., and Hubbard, J. C. 1996 Interactive effects of broccoli residue and temperature on Verticillium dahliae microsclerotia in soil and on wilt in cauliflower. Phytopathology $86: 1303-1310$

25. Subbarao, K. V., Hubbard, J. C., Hao, J. J., and Schulbach, K. F. 1995. Effects of irrigation and tillage on spatial dynamics of Sclerotinia minor sclerotia and lettuce drop incidence. (Abstr.) Phytopathology 85:1122.

26. Subbarao, K. V., Hubbard, J. C., and Schulbach, K. F. 1997. Comparison of lettuce diseases and yield under subsurface drip and furrow irrigation. Phytopathology 87:877-883.

27. Subbarao, K. V., Koike, S. T., and Hubbard, J. C. 1996. Effects of deep plowing on the distribution and density of Sclerotinia minor sclerotia and lettuce drop incidence. Plant Dis. 80:28-33.

28. Xiao, C. L., Hao, J. J., and Subbarao, K. V. 1997. Spatial patterns of microsclerotia of Verticillium dahliae in soil and Verticillium wilt of cauliflower. Phytopathology 87:325-331.

29. Xiao, C. L., Subbarao, K. V., Schulbach, K. F. and Koike, S. T. 1998. Effects of crop rotation and irrigation on Verticillium dahliae microsclerotia in soil and wilt in cauliflower. Phytopathology 88:1046-1055. 